\title{
Retrieval of HPV oncogenes E6 and E7 mRNA from cervical specimens using a manual open technology protocol
}

\author{
Leonardo Martins Campbell ${ }^{*}$, Denise Rocha Pitta ${ }^{2}$, Angela Maria De Assis², Sophie Francoise Mauricette Derchain², \\ Elisabete Aparecida Campos ${ }^{2}$ and Luis Otavio Zanatta Sarian²
}

\begin{abstract}
Background: HPV oncogenes mRNA detection gains momentum as an adjuvant for HPV-related cervical abnormalities diagnosis, but is based on costly detection assays not allowing viral type targeting.

Objective: To assess detection rate of HPV oncogenes E6/E7 mRNA from cervical specimens using a manual, open technology, fully customizable protocol and determine whether HPV-related epidemiological features influence mRNA retrieval. We reviewed literature and compared our retrieval rate with automated technologies.

Methods: We used 60 samples positive for HPV DNA types 16, 18, 31 and/or 45. We extracted mRNA with a TRizol-based protocol, and tested mRNA purity and concentration using light absorbance. We reverse-transcribed mRNA into cDNA for E6/7 detection.
\end{abstract}

Results: HPV oncogenes E6/E7 mRNA was retrieved from 36 (60\%) out of 60 specimens. No HPV load-related clinical or epidemiological feature was significantly associated with mRNA retrieval. Presence of HPV-DNA 16/18 was associated with mRNA retrieval (OR=9.08; 95\% Cl 1.26 to 65.32 for HPV 16; and 18.2; IC95\% 1.86 to 391.44 for HPV 18).

Conclusions: The open-technology protocol yielded an mRNA detection rate similar to that of automated technologies. Advantages are lower costs and target HPV type customization.

\section{Introduction}

In the last two decades, the detection of Human papillomavirus (HPV) DNA in cervical samples has proven to be a good diagnostic and risk predictor tool for cervical intraepithelial neoplasia (CIN) and cervical cancer (Castle et al. 2011). Some studies suggest that HPV oncogenes E6 and E7 mRNA levels in the uterine cervix may be more specific early indicators of predisposition to carcinogenesis than DNA levels (Benevolo et al. 2011; Ratnam et al. 2011; Winer et al. 2009). This may be due to the fact that the oncogenic potential of the high-risk HPV types (hr-HPV) relies on the actions of oncoproteins coded by E6/E7, which bind to and modulate different gene products, in particular tumor suppressors p53 and pRb (Halfon et al. 2010; Kraus et al. 2006). These interactions can lead to

\footnotetext{
* Correspondence: leo.m.campbell@gmail.com

'Gynecologic Oncology Department, Brasilia Mothers \& Babies Hospital, SGAS 608 Mód A, Brasília, DF 70203-900, Brazil

Full list of author information is available at the end of the article
}

cell cycle control disturbances, and defective DNA repair, causing genomic instability and increased risk of malignant transformation (Cattani et al. 2009; Münger \& Howley 2002).

However, the potential use of HPV oncogenes' mRNA detection in clinical practice still needs robust confirmatory studies. One of the major limiting factors for the development of such studies is the fact that in order to determine mRNA levels in cervical specimens, one must rely on a handful of detection assays, which display different performance profiles. Most currently marketed assay options for mRNA detection use proprietary technology, and feature a pre-specified and non-customizable set of target HPV types. The PreTect HPV-Proofer (NorChip) and the NucliSENS Easy Q HPV (bioMérieux) are based on the same technology, and detect E6/E7 mRNA expression from the five most prevalent hrHPV types $(16,18,31$, 33 and 45). Other two tests aim at an expanded HPV types set: the TaqMan real-time PCR assay, which targets 
12 high-risk (HPV16, 18, 31, 33, 35, 39, 45, 51, 52, 56, 58, 59) and two low-risk (HPV 6 and 11) types using E6/E7 region primers and probes in a duplex format (Andersson et al. 2011; Lindh et al. 2007), and the APTIMA HPV Assay (Gen-Probe) targets mRNA expression of the 14 most carcinogenic hr-HPV types (Burger et al. 2011; Dockter et al. 2009). However, the prevalence of HPV types may vary between female populations and the prespecified set of HPV types in a given test may prove inadequate in some epidemiological scenarios. Also importantly, the use of proprietary technology hinders the development of assay adaptations to laboratory and economic local conditions. The costs of the currently available commercial assays may not be compatible with resources available to many routine laboratories, especially in economically disadvantaged regions which, paradoxically, are heavily burdened by HPV-related diseases.

We intend to improve the efficacy and lower the cost of HPV oncogene detection, in this report we try to demonstrate how the detection rate of HPV oncogenes E6 and E7 mRNA from cervical specimens can be assessed using a manual open technology protocol, and determine whether the key epidemiological factors related to HPV viral load influence its mRNA retrieval rate.

\section{Materials and methods}

\section{Sample and data collection}

This study was carried out at the colposcopy clinics of Campinas State University (Unicamp), Brazil, a public health institution dedicated to comprehensive care for women, was approved by the local Ethics Committee (Protocol: $\mathrm{N}^{\circ}$ CEP 723/2009) in compliance with the recommendations of the "Declaration of Helsinki" for guiding medical doctors in biomedical research involving human subjects. The samples consisted of cervical specimens, collected from women who underwent cervical diathermic conization due to HPV-induced squamous lesions at Unicamp's cervical pathology clinics. Women were invited to participate while awaiting the conization procedure. Every research subject signed a written informed consent stating their compliance with the study, and an interview was performed concerning clinical and epidemiological aspects. After that, and immediately before the conization procedure, a cervical specimen was obtained with an endocervical brush, and stored in a 1-mL tube containing Specimen Transport Medium (STM, Qiagen Inc.).

In order to obtain the sample for these experiments we examined 117 specimens between April and December 2010. We first performed PCR reactions in order to ascertain the presence of HPV DNA using standard protocols (Swan et al. 1999). Of the 117 original cases 74 were positive for HPV DNA (PGMY 9/11). We next performed PCR reactions in order to ascertain the presence of DNA of the following HPV types: 16, 18, 31 and/or 45. Samples not harboring at least one of the HPV types of interest were discarded, and the patient excluded from the study. After completing 60 samples positive for at least one HPV type, we closed the accrual phase of the study (estimated sample size, considering 95\% confidence intervals and $80 \%$ Beta power, for an estimated difference in mRNA levels of $20 \%$ between women harboring different HPV types, was 58 ). We then proceeded to the next phase of the study: detection of the mRNA in the samples.

\section{mRNA extraction}

As mentioned earlier, only samples positive for DNA of HPV types 16, 18, 31 and 45 were tested for mRNA. For mRNA extraction, an aliquot of $200 \mathrm{ul}$ of STM was sampled (Qiagen) and centrifuged at 13,000 g for $10 \mathrm{~min}$. The supernatant was removed and $1 \mathrm{~mL}$ of the TRizol $^{\text {ix }}$ reagent (Invitrogen, Carlsbad, USA) was added to the cellular pellet, and cells lysed by repeat pipetting and standing at room temperature for $5 \mathrm{~min}$ (TRizol is the most widely used reagent in the public setting in Brazil, hence its choice). Subsequently, 200 ul of chloroform was added and shaken vigorously, standing at room temperature for $3 \mathrm{~min}$ before centrifugation at 12,000 $\mathrm{g}$ for $15 \mathrm{~min}$. The resultant aqueous layer was then transferred to a new tube. To the aqueous solution, a volume of $500 \mu \mathrm{l}$ of isoamyl alcohol was added and mixed by vortex. The whole mixture stood at $-80^{\circ} \mathrm{C}$ for 2 hours and $10 \mathrm{~min}$ at room temperature and centrifuged at $12,000 \mathrm{~g}$ for $10 \mathrm{~min}$. Supernatant was then removed and $1 \mathrm{~mL}$ of iced ethanol was added and shaken vigorously. Finally, the mixture was centrifuged at $7,500 \mathrm{~g}$ for $5 \mathrm{~min}$, the supernatant was removed and after the pellet of mRNA was dry, mRNA was eluted in $30 \mu \mathrm{l}$ of mRNAase-free water (DEPC) and stored at $-80^{\circ} \mathrm{C}$ pending analysis. The mRNA purity and concentration were determined by the absorbance at $260 \mathrm{~nm}$ (A260) and $280 \mathrm{~nm}$ (A280) using NanoDrop ND-1000 (Thermo Fisher Scientific, Waltham, MA).

\section{Type-specific PCR for HPV 16, 18, 31 and 45 oncogenes E6 and $E 7$ mRNA}

PCR products were visualized using agarose gel electrophoresis. The reactions were performed separately according to the reagent mixture: five $\mu \mathrm{l}$ of DNA were added to a PCR mix containing 0.5 pmol of each primer (Table 1), specifically designed by the investigators for the present study, $4.0 \mathrm{mM} \mathrm{MgCl} 2,0.25 \mathrm{mM}$ dNTPs and 5 units of Taq platinum in a final $50 \mu \mathrm{l}$ volume. Every step of the PCR reactions was similar, except to annealing temperature which was different for each type HPV. During each PCR run, samples were tested altogether with one negative (water) and one positive control (obtained in prior studies). A 9-min denaturation step at $95^{\circ} \mathrm{C}$ was followed 
Table 1 Primers designed for E6/E7 mRNA detection

\begin{tabular}{|c|c|c|c|}
\hline HPV & Region & Size & Sequence \\
\hline \multirow[t]{2}{*}{16} & E6 & $\pm 659 \mathrm{pb}$ & 5' TAAAACTAAGGGCGTAACCG 3' \\
\hline & & & 5' TCTATTTCATCCTCCTCCTCTG 3' \\
\hline \multirow[t]{2}{*}{16} & E7 & $\pm 491 \mathrm{pb}$ & 5' ACTGTGTCCTGAAGAAAAGCAA 3' \\
\hline & & & 5' AACCATCCATTACATCCCGT 3' \\
\hline \multirow[t]{4}{*}{18} & E6 & $\pm 608 \mathrm{pb}$ & 5' TAGGTTGGGCAGCACATACT 3' \\
\hline & & & 5' ATACTTGTGTTTCTCTGCGTCG 3' \\
\hline & E7 & $\pm 358 \mathrm{pb}$ & 5' CGACGCAGAGAAACACAAGTAT 3' \\
\hline & & & 5' ATTGTTGCTTACTGCTGGGAT 3' \\
\hline \multirow[t]{4}{*}{31} & E6 & $\pm 606 \mathrm{pb}$ & 5' AAGTAGGGAGTGACCGAAAGT 3' \\
\hline & & & 5' ACAGTGGAGGTCAGTTGCC 3' \\
\hline & E7 & $\pm 437 \mathrm{pb}$ & 5' AGGCACGGCAAGAAAGACT 3' \\
\hline & & & 5' AAAGAACCAGCCATTACACC 3' \\
\hline \multirow[t]{4}{*}{45} & E6 & $\pm 659 \mathrm{pb}$ & 5' ATACTACATAAAAAAGGGTG $3^{\prime}$ \\
\hline & & & $5^{\prime}$ TCGTAACACAACAGGTCAACA $3^{\prime}$ \\
\hline & E7 & $\pm 439 \mathrm{pb}$ & 5' AGGCACGGCAAGAAAGACT 3' \\
\hline & & & 5' AAAGAACCAGCCATTACACC $3^{\prime}$ \\
\hline
\end{tabular}

by 40 cycles of amplification. Each cycle included a denaturation step at $95^{\circ} \mathrm{C}$ for $1 \mathrm{~min}$, a primer annealing step for each HPV type for $1 \mathrm{~min}$, and a chain elongation step at $72^{\circ} \mathrm{C}$ for 1 minute. The final elongation step was prolonged by $7 \mathrm{~min}$ to ensure complete amplified DNA extension.

\section{CDNA transcription}

The mRNA was reverse-transcribed into first strand cDNA (SuperScript III First Strand Synthesis System, Invitrogen) according to the manufacturer's guidelines. The cDNA PCR product was amplified as described in the typespecific PCR section, although with a final volume of $25 \mu \mathrm{l}$ and $2 \mu \mathrm{l}$ of cDNA.

\section{Statistical analysis}

All statistical analyses were performed with the R Environment for Statistical Computing (R Project). Significance was set at $95 \%(\mathrm{p}=0.05)$ and $95 \%$ confidence intervals were used $(95 \% \mathrm{CI})$. We constructed a multivariate regression model assessing HPV oncogenes E6 and E7 mRNA retrieval according to clinical features and presence of HPV DNA of types 16, 18, 31 and/or 45. Odds ratios were obtained by exponentiation of the regression coefficients.

\section{Results}

We retrieved oncogenes E6 and E7 mRNA from 36 (60\%) of the 60 specimens previously found to be positive for the relevant HPV genotypes. None of the classically viral load related clinical and epidemiological features that have been repeatedly reported in the medical literature was significantly associated with mRNA retrieval (Benevolo et al. 2011;
Kraus et al. 2006). The presence of HPV 16 and 18 in the sample was positively associated with mRNA retrieval $(\mathrm{OR}=\mathrm{p}<9.08$; $95 \%$ CI 1.26 to 65.32 for HPV 16; and 18.2; IC $95 \% 1.86$ to 391.44 for HPV 18). Presence of other HPV genotypes was not associated to mRNA retrieval at the same rate, and associations were not significant at the $95 \%$ threshold (Table 2).

Table 3 lists key findings of major studies addressing mRNA detection rate in HPV DNA positive cervical specimens. Our detection rate of $60 \%$ is comparable to that reported by (Halfon et al. 2010) (68.5\%) and (Ratnam et al. 2011) (68\%), who used the automated NucliSens Easy Q HPV Assay BioMerieux and Aptima HPV detection assays, respectively. Those detection assays are targeted to HPV types $16,18,31,33$ and 45 , which is basically the

Table 2 Recovery of viable E6/E7 mRNA according to key clinical features of the women and cyto-histological characteristics of the samples

\begin{tabular}{|c|c|c|c|c|c|c|c|}
\hline \multirow[b]{2}{*}{ Characteristic } & \multicolumn{4}{|c|}{ mRNA E6 or E7 } & \multirow[b]{2}{*}{ OR } & \multirow[b]{2}{*}{$(95 \% \mathrm{Cl})$} & \multirow[b]{2}{*}{$p$} \\
\hline & neg & (\%) & pos & (\%) & & & \\
\hline \multicolumn{8}{|l|}{ Age } \\
\hline$<30$ & 14 & $(58.3)$ & 16 & $(44.4)$ & 4.18 & (0.87 to 20.05 ) & 0.07 \\
\hline$>30$ & 10 & $(41.7)$ & 20 & $(55.6)$ & 1.0 & & \\
\hline
\end{tabular}

First intercourse

$\begin{array}{llllllll}<16 & 14 & (58.3) & 19 & (52.8) & 0.73 & (0.2 \text { to } 2.72) & 0.637\end{array}$

$\begin{array}{llllll}>16 & 10 & (41.7) & 17 & (47.2) & 1.0\end{array}$

Lifetime sex partners

\begin{tabular}{|c|c|c|c|c|c|c|c|}
\hline$>2$ & 5 & (20.8) & 9 & (25) & 0.55 & (0.11 to 2.69$)$ & 0.461 \\
\hline-2 & 19 & $(79.2)$ & 27 & (75) & 1.0 & & \\
\hline \multicolumn{8}{|l|}{ Current smoker } \\
\hline 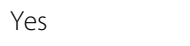 & 8 & (33.3) & 11 & $(30.6)$ & 0.8 & (0.2 to 3.18 ) & 0.751 \\
\hline & 16 & $(66.7)$ & 25 & $(69.4)$ & 1.0 & & \\
\hline \multicolumn{8}{|l|}{ ytology } \\
\hline $\mathrm{C}-\mathrm{H}$ or HSIL & 19 & $(79.2)$ & 27 & (75) & 0.36 & (0.06 to 2.02 ) & 0.245 \\
\hline C-US or LSIL & 5 & (20.8) & 9 & (25) & 1.0 & & \\
\hline \multicolumn{8}{|l|}{ istology } \\
\hline V2-CIN3 & 21 & $(87.5)$ & 35 & $(97.2)$ & 5.43 & (0.24 to 124.79$)$ & 0.290 \\
\hline vivitis-CIN1 & 3 & $(12.5)$ & 1 & $(2.8)$ & 1.0 & & \\
\hline
\end{tabular}

HPV Type-specific mRNA transcription***

DNA-HPV 16

$\begin{array}{lllllllll}\text { Positive } & 17 & (40.4) & 25 & (59.6) & 9.08 & (1.26 \text { to } & 65.32) & 0.028\end{array}$

DNA HPV 18

$\begin{array}{lllllllll}\text { Positive } & 2 & (28.5) & 5 & \text { (71.5) } & 18.27 & \text { (1.86 to 392.44) } & 0.033\end{array}$

DNA HPV 31

$\begin{array}{lllllllll}\text { Positive } & 14 & (54.4) & 12 & (45.6) & 3.18 & (0.68 \text { to } 14.89) & 0.142\end{array}$ DNA HPV 45

$\begin{array}{llllllll}\text { Positive } \quad 5 & 5 & (50.0) & 5 & (50.0) & 13.45 & \text { (0.73 to 246.64) } & 0.080\end{array}$

${ }^{*}$ As per study design samples negative for a given HPV type were not re-tested for that type-specific mRNA; **percentages in rows. 
Table 3 Studies assessing mRNA retrieval from HPV-DNA positive cervical samples using currently available detection assays

\begin{tabular}{|c|c|c|c|c|c|}
\hline Author & Year & Detection technique & Automation & HPV types included in assay & E6/E7 mRNA detection rate \\
\hline Molden & 2005 & Pre-Tec HPV Proofer NASBA & Automated & 1618313345 & $98 / 429(228 \%)$ \\
\hline Catani & 2009 & NucliSens Easy Q HPV Assay BioMerieux & Automated & 1618313345 & $81 / 180(45 \%)$ \\
\hline Dockter* & 2009 & Aptima HPV Assay Tigris DST System & Semi-automated & 16183133353945515256585966 and 68 & 407/443 (919\%) \\
\hline Dockter* & 2009 & Aptima HPV Assay DST & Automated & 16183133353945515256585966 and 68 & $410 / 443(926 \%)$ \\
\hline Halfon & 2010 & NucliSens Easy Q HPV Assay BioMerieux & Automated & 1618313345 & $61 / 89(68.5 \%)$ \\
\hline Monsonego & 2010 & Aptima HPV Assay & Automated & 16183133353945515256585966 and 68 & $456 / 4429(10.3 \%)$ \\
\hline Benevolo & 2011 & Pre-Tec HPV Proofer NASBA & Automated & 1618313345 & $162 / 464(36 \%)$ \\
\hline Ratnam & 2011 & Aptima HPV Assay & Automated & 16183133353945515256585966 and 68 & $964 / 1418(68 \%)$ \\
\hline Our study & 2012 & Homebrew low-cost TRizol protocol & Manual & 16183145 & $36 / 60(60 \%)$ \\
\hline
\end{tabular}

*Both APTIMA tests were compared in the same publication. 
same set of HPV types addressed in our experiments, except for HPV 33. (Dockter et al. 2009) compared the performance of the fully automated Aptima HPV Assay DST with that of the semi-automated Aptima HPV Assay Tigris DST System. In samples previously tested for HPV DNA with Hybrid Capture 2, they achieved $92.6 \%$ and 91.9\% E6/E7 mRNA detection rates, respectively. However, those assays target $14 \mathrm{HPV}$ types. (Molden et al. 2005) and (Benevolo et al. 2011) using the Pre-Tec HPV Proofer NASBA reported $22.8 \%$ and $36.0 \%$ mRNA detection rates, respectively.

\section{Discussion}

In our study, using open technology protocols (which, thanks to their relatively low-cost are appropriate for low-resource settings), we retrieved viable oncogenes E6 and E7 mRNA in almost $60 \%$ of the HPV DNA positive cases. The extraction technique was completely manual. There are plenty of reports on this subject using automated our semi-automated detection techniques, with manufacturer prespecified sets of HPV types included in the assay. Our mRNA detection rate was comparable to those reported by most authors using automated mRNA detection techniques (Benevolo et al. 2011; Cattani et al. 2009). Using proprietary technology protocols, such as the PreTect HPV-Proofer (NorChip) and the NucliSENS Easy Q HPV (bioMérieux), studies similar to ours achieved overall mRNA retrieval rates ranging from $36 \%$ to $68 \%$ (Benevolo et al. 2011; Ratnam et al. 2011; Halfon et al. 2010; Cattani et al. 2009; Dockter et al. 2009; Molden et al. 2005; Monsonego et al. 2010). Therefore, our results seem to point out to a reliable and not too expensive way of detecting mRNA. Larger and prospective studies might well confirm the reliability of open technology protocols for mRNA detection and underscore its indications in clinical and laboratory practice. Also worth noting, open technology manual techniques could allow tailoring experiments to the HPV epidemiological profile (i.e. the most prevalent HPV types) of the population under scrutiny.

Our study has some limitations, including a lack of cytology - histology - mRNA detection which was not included at this time and this also limits the comparison of our retrieval technique with other methods. Therefore a comparison with pathological samples from other publications was also not possible at this time. Another limitation of our study is that we also did not perform a comparison with other assays using the same sample set. Finally, another caveat of this study was that we did not perform a breakdown of all HPV genotypes present in each samples (for times more than one), what could point out to an association of multiple genotypes and mRNA.

However, scientific evidence accumulated from virological, molecular, clinical and epidemiological studies has unequivocally demonstrated that cervical cancer is in fact a sequel from a long term unresolved infection by certain HPV genotypes (Castellsagué 2008). In the largest multinational studies performed so far, HPV types 16,18 , 31,33 and 45 were shown to be the most prevalent types associated with cervical carcinomas, HPV 16 alone found in more than $50 \%$ of cases (Kraus et al. 2006; Bosch et al. 1995). In North India, HPV 16 was by far the commonest single type in all histological categories. Similar results have been reported in other studies (Bhatla et al. 2008). Studies using quantitative type-specific PCR for high-risk HPV 16, 18, 31, 33, and 45 and low-risk HPV 6 and 11 have shown that HPV 16 can reach much higher viral loads than the other types and that only for HPV 16 does increased viral load correlate with increased severity of cervical disease (Burd 2003). However, questions do remain as to how better oncogene mRNA transcription rates favor the carcinogenic potential of some HPV types, and to which individual patient characteristics may be involved in the DNA-to-mRNA transcription rates.

Despite the substantial resources spent in cytology screening and follow-up, cervical cancer is still the 10th most common cause of cancer death in European women. In Brazil by contrast, although rapidly declining, cervical cancer is one of the leading causes of mortality among women, and the cervical cancer burden is even heavier in less developed countries. Because cervical cancer is the only cancer that is almost completely preventable through regular screening and thus early treatment, improvement and expansion of existing screening strategies and technologies constitutes a main target of the European Council Recommendation on Cancer Screening (Boulet et al. 2008). However, many of the proposed screening strategies, due to resource constraints, may not be applicable worldwide. A test that can reliably differentiate between transient and persistent infections would allow additional effective cervical cancer policies targeting its prevention (Burger et al. 2011) which would be very welcomed. Detection of mRNA in cervical samples may probably serve this purpose, for the aforementioned reasons.

Current lines of evidence reinforce the biological reasons for detecting HPV oncogenes E6 and E7 mRNA. HPV screening cohort studies have shown that HPV DNA testing has a higher sensitivity than cytological testing for the detection of cervical lesions, although it has slightly lower specificity (Halfon et al. 2010). Its sensitivity for moderate dysplasia or worse is lower, but the specificity is higher (Cattani et al. 2009; Keegan et al. 2009; Szarewski et al. 2008). It is well-known that many cervical lesions with moderate or severe dysplasia will regress spontaneously. Only $31 \%$ of colposcopically visible lesions with severe dysplasia will progress to invasive cancer within 30 years (McCredie et al. 2008). Changes such as integration of viral DNA (which stabilizes the expression 
of E6 and E7) are virus specific, associated with the malignant progression of the tumor. Other changes include the alteration of cellular genes, leading to downregulation of tumor suppressor genes and proapoptotic genes or upregulation of proto-oncogenes or antiapoptotic genes. These alterations reflect the effects of prolonged viral gene expression, in particular viral proteins E6 and E7 (Snijders et al. 2006). In productive HPV infections, which appear cytologically as LSIL and histologically as CIN1, the expression of viral E6 and E7 oncogenes is tightly regulated, with high-level expression only in suprabasal postmitotic cells. On the other hand, in high-grade CIN and cancer, E6 and E7 are expressed throughout the thickness of the cervical epithelium (Stanley 2008).

Given the fact that sustained viral oncogenes E6 and E7 expression is essential for the initiation and maintenance of the transformed phenotype induced by mucosal high-risk HPVs, several assays have been specifically developed for the detection of HPV E6E7 mRNA (Snijders et al. 2010), despite the fact that positivity rates of the HPV mRNA test are one third that of HPV DNA tests. Increased knowledge concerning the molecular biology of cervical carcinogenesis raises expectations that biomarkers will result in a more accurate diagnosis of cervical cancer (Horvath et al. 2008). Moreover, the emergence of molecular medicine has resulted in the increased use of RNA in clinical diagnostics (Cuschieri et al. 2005). The identification of persistent infections has become a primary target for HPV mRNA testing because infections that do not regress are more likely to lead to cellular changes of the cervix, pre cancer lesions and/or invasive cervical cancer.

DNA and mRNA testing may be employed together for screening to take advantage of the combined higher sensitivity and specificity these tests have shown; patients would e.g. then be referred for a biopsy when both tests were positive (Halfon et al. 2010). Although the combined use of DNA and mRNA is a promising alternative for the improvement of molecular-biology based screening of cervical abnormalities, proprietary technology costs may preclude its implementation in low-resource settings. Furthermore, the use of assays targeted at a prespecified set of HPV types may be a waste of resources in regions with a different HPV type distribution. For the above mentioned reasons, the potential for clinical applicability of mRNA detection in low-resource settings seems to be large.

\section{Abbreviations}

STM: Specimen transport medium; DEPC: Diethylpyrocarbonate water; PGMY: Primer system; ASC-H: Atypical squamous cells - cannot exclude HSIL; HSIL: High grade squamous intraepithelial lesion; ASC-US: Atypical Squamous Cells of Undetermined Significance; LSIL: Low grade squamous intraepithelial lesion; CIN2: Cervical intraepithelial neoplasia grade 2: CIN3: Cervical intraepithelial neoplasia grade 3; Cervicitis: Inflammation of the uterine cervix inflammation of the uterine cervix; CIN1: Cervical intraepithelial neoplasia grade 1.

\section{Competing interests}

The authors declare that they have no competing interests.

\section{Authors' contributions}

LMC: research, English translation, journal submission. DRP: laboratory research. AMDA: laboratory research. SFMD: study design, supervision. EAP: laboratory research. LOZS: statistical calculations. All authors read and approved the final manuscript.

\section{Acknowledgments}

This research was funded by the "Fundação de Amparo à Pesquisa do Estado de São Paulo" (FAPESP). Authorization number for this research was: 2009/11248-8.

\section{Disclosure}

All authors hereby declare approval to this article in its final form.

\section{Author details}

'Gynecologic Oncology Department, Brasilia Mothers \& Babies Hospital, SGAS 608 Mód A, Brasília, DF 70203-900, Brazil. ²Department of Obstetrics and Gynecology, Campinas State University, Campinas, Brazil.

Received: 27 August 2013 Accepted: 17 September 2013 Published: 18 September 2013

\section{References}

Andersson E, Kärrberg C, Rädberg T, Blomqvist L, Zetterqvist BM, Ryd W, Lindh M, Horal P (2011) Type-specific human papillomavirus E6/E7 mRNA detection by Real-Time PCR improves identification of cervical neoplasia. J Clin Microbiol 49(11):3794-9

Benevolo M, Vocaturo A, Caraceni D, French D, Rosini S, Zappacosta R, Terranatos I, Ciccocioppo L, Frega A, Rossi PG (2011) Sensitivity specificity and clinical value of (HPV) E6/E7 mRNA assay as a triage test for cervical cytology and HPV DNA test. J Clin Microbiol 49(7):2643-50

Bhatla N, Dar L, Rajkumar Patro A, Kumar P, Pati SK, Kriplani A, Gulati A, Broor S, lyer VK, Mathur S, Shah KV, Gravitt PE (2008) Human papillomavirus-type distribution in women with and without cervical neoplasia in north India. Int J Gynecol Pathol 27(3):426-30

Bosch FX, Manos MM, Munoz N, Sherman M, Jansen AM, Peto J, Schiffman MH, Moreno V, Kurman R, Shah KV (1995) Prevalence of human papillomavirus in cervical cancer: a worldwide perspective. International biological study on cervical cancer (IBSCC) study group. J Natl Cancer Inst 87:796-802

Boulet GA, Horvath CA, Berghmans S, Bogers J (2008) Human papillomavirus in cervical cancer screening: important role as biomarker. Cancer Epidemiol Biomarkers Prev 17(4):810-7

Burd EM (2003) Human papillomavirus and cervical cancer. Clin Microbiol Rev 16(1):1-17

Burger EA, Kornor H, Klemp M, Lauvrak V, Kristiansen IS (2011) HPV mRNA tests for the detection of cervical intraepithelial neoplasia: a systematic review. Gynecol Oncol 120(3):430-8

Castellsagué X (2008) Natural history and epidemiology of HPV infection and cervical cancer. Gynecol Oncol 110:S4-S7

Castle PE, Gutierrez EC, Leitch SV, Maus CE, McMillian RA, Nussbaumer WA, Vaughan LM, Wheeler CM, Gravitt PE, Schiffman M (2011) Evaluation of a new DNA test for detection of carcinogenic human papillomavirus. J Clin Microbiol 8:3029-3032

Cattani P, Siddu A, D'Onghia S, Marchetti S, Santangelo R, Vellone VG, Zannoni GF, Fadda G (2009) RNA (E6 and E7) assays versus DNA (E6 and E7) assays for risk evaluation for women infected with human papillomavirus. J Clin Microbiol 47(7):2136-2141

Cuschieri KS, Beattie G, Hassan S, Robertson K, Cubie H (2005) Assessment of human papillomavirus mRNA detection over time in cervical specimens collected in liquid based cytology medium. J Virol Methods 124:211-215

Dockter J, Schoroder A, Hill C, Guzenski L, Monsonego J, Giachetti C (2009) Clinical performance of the APTIMA ${ }^{\oplus}$ HPV assay for the detection of high-risk HPV and high-grade cervical lesions. J Clin Virol 45(Suppl 1):S55-S61 
Halfon P, Benmoura D, Agostin A, Khiri H, Martineau A, Penaranda G, Blanc B (2010) Relevance of HPV mRNA detection in a population of ASCUS plus women using the NucliSENS EasyQ HPV assay. J Clin Virol 47:177-181

Horvath C, Boulet G, Sahebali S, Bogers J, Depuyd C, Vereecken A, Vermeulen T, Vanden Broeck D (2008) Effects of fixation on RNA integrity in a liquid-based cervical cytology setting. J Clin Pathol 61:132-137

Keegan H, Mclnerney J, Pilkington L, Gronn P, Silva I, Karlsen F, Bolger N, Logan C, Furuberg L, O'Leary J, Martina C (2009) Comparison of HPV detection technologies: hybrid capture 2 PreTectTM HPV-proofer and analysis of HPV DNA viral load in HPV16 PV18 and HPV33 E6/E7 mRNA positive specimens. J Virol Methods 155:61-66

Kraus I, Molden T, Holm R, Lie K, Karlsen F, Kristensen GB, Skomedal H (2006) Presence of E6 and E7 mRNA from human papillomavirus types 16, 18, 31, 33 and 45 in the majority of cervical carcinomas. J Clin Microbiol 44 (4):1310-1317

Lindh M, Görander S, Andersson E, Horal P, Mattsby-Balzer I, Ryd W (2007) Real-time Tagman PCR targeting 14 human papilloma virus types. J Clin Virol 40(4):321-4

McCredie MR, Sharples KJ, Paul C, Baranyai J, Medley G, Jones RW, Skegg DC (2008) Natural history of cervical neoplasia and risk of invasive cancer in women with cervical intraepithelial neoplasia 3: a retrospective cohort study. Lancet Oncol 9(5):425-34

Molden T, Kraus I, Karlsen F, Skomedal H, Nygård JF, Hagmar B (2005) Comparison of human papillomavirus messenger RNA and DNA detection: a cross-sectional study of 4136 women $>30$ years of age with a 2-year follow-up of high-grade squamous intraepithelial lesion. Cancer Epidemiol Biomarkers Prev 14(2):367-72

Monsonego J, Hudgens MG, Zerat L, Zerat JC, Syrjanen K, Halfon P, Ruiz F, Smith JS (2010) Evaluation of oncogenic human papillomavirus RNA and DNA tests with liquid-based cytology in primary cervical cancer screening: the FASE study. Int J Cancer 129:691-701

Münger K, Howley PM (2002) Human papillomavirus immortalization and transformation functions. Virus Res 89(2):213-28

Ratnam S, Coutlee F, Fontaine D, Bentley J, Escott N, Ghatage P, Gadag V, Holloway G, Bartellas E, Kum N, Giede C, Lears A (2011) Aptima HPV E6/E7 mRNA test is as sensitive as hybrid capture 2 assay but more specific at detecting cervical precancer and cancer. J Clin Microbiol 49(2):557-564

Snijders PJ, Hogewoning CJ, Hesselink AT, Berkhof J, Voorhorst FJ, Bleeker MC, Meijer CJ (2006) Determination of viral load thresholds in cervical scrapings to rule out CIN 3 in HPV 16, 18, 31 and 33-positive women with normal cytology. Int J Cancer 119:1102-1107

Snijders PJ, Heideman DA, Meijer CJ (2010) Methods for HPV detection in exfoliated cell and tissue specimens. APMIS 118:520-528. doi:10.1111/j.1600-0463.2010.02621 x

Stanley M (2008) Immunobiology of HPV and HPV vaccines. Gynecol Oncol 109:S15-S21

Swan DC, Tucker RA, Tortolero-Luna G, Mitchell MF, Wideroff L, Unger ER, Nisenbaum RA, Reever WC, Icenogle JP (1999) Human papillomavirus (HPV) DNA copy number is dependent on grade of cervical disease and HPV Type. J Clin Microbiol 37(4):1030-4

Szarewski A, Ambroisine L, Cadman L, Austin J, Ho L, Terry G, Liddle S, Dina R, McCarthy J, Buckley H, Bergeron C, Soutter P, Lyons D, Cuzick J (2008) Comparison of predictors for high-grade cervical intraepithelial neoplasia in women with abnormal smears. Cancer Epidemiol Biomarkers Prev 17(11):3033-42

Winer RL, Harris TG, Xi LF, Jansen KU, Hughest JP, Feng Q, Welebob C, Ho J, Lee SK, Carter JJ, Galloway DA, Kiviat NB, Koutsky LA (2009) Quantitative human papillomavirus 16 and 18 levels in incident infections and cervical lesion development. J Med Virol 81:713-721

doi:10.1186/2193-1801-2-473

Cite this article as: Campbell et al:: Retrieval of HPV oncogenes E6 and E7 mRNA from cervical specimens using a manual open technology protocol. SpringerPlus 2013 2:473

\section{Submit your manuscript to a SpringerOpen ${ }^{\circ}$ journal and benefit from:}

- Convenient online submission

- Rigorous peer review

- Immediate publication on acceptance

- Open access: articles freely available online

- High visibility within the field

- Retaining the copyright to your article

Submit your next manuscript at $>$ springeropen.com 